\title{
Logical Function of Rhetorical Questions: An Enthymematic Analysis of RQs in The Literary Mind and the Carving of Dragons
}

\author{
Qian Na, Ying Yuan* \\ School of Foreign Languages, Soochow University, China
}

Copyright $\mathrm{C} 2019$ by authors, all rights reserved. Authors agree that this article remains permanently open access under the terms of the Creative Commons Attribution License 4.0 International License

\begin{abstract}
Rhetorical questions are often interpreted from the semantic, pragmatic, and syntactical perspectives; but their logical function is rarely investigated. This paper, based on the proper interpretation of Aristotle's "enthymeme" or "rhetorical syllogism", attempts to explore the mechanism of RQs' argumentative function, by examining the RQ-rich masterpiece, Liu Xie's The Literary Mind and the Carving of Dragons (《文心雕龙》). The sample analyses reveal that RQs achieve a strong logical function via both suggesting and implying the propositions (often major premise and conclusion), as well as providing the solid argument (as minor premise). Also, our enthymematic analyses prove that the RQs' logical function is meanwhile accompanied by salience of the suggested conclusion or major premise, the assertion or assumption transformed from the question itself. This inquiry highlights the argumentative function of rhetorical figures and enriches Western rhetoric notions in Chinese classics interpretation.
\end{abstract}

Keywords Rhetorical Question, Logical Function, Enthymeme, Liu Xie, The Literary Mind and the Carving of Dragons

\section{Introduction}

The tactic of "posing a question without expecting an answer" (Frank, 1990, p. 723) has been historically prevalent as a persuasive device, which was named "rhetorical question". In fact, many ancient rhetoricians have noticed its argumentative power. Aristotle stresses the argumentative power of Interrogation: "The best moment to employ this is when your opponent has so answered one question that the putting of just one more lands him in absurdity." 1 Similarly, Quintilian mentions that rhetorical

1 This sentence is taken from the last chapter of Rhetoric (1954, p. 215) question can "increase the force and cogency of proof" (1921, p. 377). And the first complete Latin rhetoric manual, Rhetorica ad Herennium, also notes that the view expressed in the form of rhetorical question is difficult to refute (Cicero, 1954, pp. 293-295). Contemporary rhetoricians have added their own interpretations to this classical concept. Lanham (1991), and Crowley \& Hawhee (2012) believe that rhetorical questions are not used by speakers to elicit information or a response, but to obtain stronger expressive power than direct assertions. However, we find that throughout the rhetorical history, the argumentative function of RQs has, on the whole, been just briefly or generally addressed, with few having inquired into its persuasiveness -- specifically. Inspired by Kraus' (2007) linking RQ with "enthymeme" (rhetorical syllogism), we aim to further the investigation of RQ's logical function by exploring which particular type(s) of enthymeme RQs often generate, what specific argumentative functions they mainly achieve, and why the enthymematic RQs can produce or enhance the persuasive power. The texts for analysis will be taken from Liu Xie's The Literary Mind and the Carving of Dragons or Wen Xin Diao Long (《文心雕龙》), a RQ-rich ancient Chinese masterpiece. Because of its profundity, the studies in English are still meager. Zhao (1994) initiates an inventional approach to the Carving of Dragons via two parts: content-oriented inventional acts and form-oriented inventional acts, which complement each other and are bound to circumstantial considerations. This research can be seen as resuming the investigation of form invention in The Literary Mind.

where Aristotle seems to have touched upon the link between question and enthymeme. As shown on the next page, "You cannot ask a series of questions owing to the incapacity of the audience to follow them; and for this reason you should also make your enthymemes as compact as possible." Here, "question"/Interrogation, though broader, includes rhetorical question. 


\section{Enthymeme: Incompleteness and Probability}

Enthymeme, a core concept of Western rhetoric, is regarded by Aristotle as "the substance of rhetorical persuasion", "the most effective of the modes of persuasion" (1954, pp. 20-22). But in his Rhetoric, this term is not given a formal or standard definition; instead, Aristotle calls "the enthymeme a rhetorical syllogism" (ibid: 26) and defines it with two distinct traits: incompleteness and probability.

Incompleteness means that in contrast to a standard syllogism, an enthymeme often appears with certain proposition(s) omitted, which Aristotle illustrated in detail as follows:

The enthymeme must consist of fewer propositions, fewer often than those which make up the normal syllogism. For if any of these propositions is a familiar fact, there is no need even to mention it; the hearer adds it himself. Thus, to show that Dorieus has been victor in a contest for which the prize is a crown, it is enough to say 'For he has been victor in the Olympic games', without adding 'And in the Olympic games the prize is a crown', a fact which everybody knows. (ibid: 28)

The above citation seems to offer us a rather clear explanation of enthymeme's incomplete feature. However, it still triggers controversial interpretations, especially concerning the number and type of proposition which can be omitted. The vast majority of researchers hold that enthymeme can only omit one proposition, and it is the major premise, often of common knowledge nature. Yet, we firmly believe that this is not the whole picture, as evidenced in the above example given by Aristotle himself: not only have the major premise, "in the Olympic Games the prize is a crown", is left out, but also the obvious conclusion, "Dorieus has won a crown". So we are justified to say that enthymeme can omit one to two propositions, either premise or conclusion, depending on the particular rhetorical situation. Derived from Yuan (2006), ${ }^{2}$ the following table will use Aristotle's Dorieus case to illustrate all the 6 possible incomplete forms of enthymeme/rhetorical syllogism:

Table 1. Six Incomplete Types of Enthymeme

\begin{tabular}{|c|c|c|c|c|}
\hline Number & Major Premise & Minor Premise & Conclusion & $\begin{array}{c}\text { Omitted } \\
\text { Proposition(s) }\end{array}$ \\
\hline 1 & & $\begin{array}{l}\text { Dorieus has been victor in } \\
\text { the Olympic games. }\end{array}$ & Dorieus has won a crown. & major premise \\
\hline 2 & $\begin{array}{l}\text { In the Olympic games the prize is } \\
\text { a crown. }\end{array}$ & & Dorieus has won a crown. & minor premise \\
\hline 3 & $\begin{array}{l}\text { In the Olympic games the prize is } \\
\text { a crown. }\end{array}$ & $\begin{array}{l}\text { Dorieus has been victor in } \\
\text { the Olympic games. }\end{array}$ & & conclusion \\
\hline 4 & & $\begin{array}{l}\text { Dorieus has been victor in } \\
\text { the Olympic games. }\end{array}$ & & $\begin{array}{l}\text { major premise, } \\
\text { conclusion }\end{array}$ \\
\hline 5 & $\begin{array}{l}\text { In the Olympic games the prize is } \\
\text { a crown. }\end{array}$ & & & $\begin{array}{l}\text { minor premise, } \\
\text { conclusion }\end{array}$ \\
\hline 6 & & & Dorieus has won a crown. & $\begin{array}{l}\text { major premise, } \\
\text { minor premise }\end{array}$ \\
\hline
\end{tabular}

2 Yuan (2006), after a close study of Aristotle's enthymeme, claims that there are 7 forms of enthymeme, including one complete form and six incomplete forms, illustrated by the "Noble" enthymeme in Ch. 9, BI of Rhetoric. Yuan \& Jiang (2010) confirms these 7 types, illustrated by the "Gold" enthymeme in Ch. 7, BI. But a complete form must satisfy the other feature, probability; otherwise it cannot be called a rhetorical syllogism. Then, for enthymeme with the factual nature, as shown in the case of "Dorieus", people do not use the complete form. So here is a revised table: "Six Incomplete Types of Enthymeme", which suits both the probable and the factual, with the typical illustration of "Dorieus" in Ch. 2, BI. 
Although all the six truncated types of rhetorical syllogism are possible, different purposes will lead to different choices. In terms of conciseness, Types 4, 5, 6 are preferred, especially in daily conversations; with regard to seriousness, then the first three types should be employed more frequently; and concerning subtlety or euphemism, Types 3, 4, 5 are definitely favored, especially when the conclusion is discouraging or negative. As we see, one incomplete type can achieve different functions which are not confined to what we have mentioned.

Probability suggests the "contingent" nature of enthymeme or rhetorical syllogism in contrast to the "necessary" feature of standard syllogism, the reason of which is stated as below:

There are few facts of the 'necessary' type that can form the basis of rhetorical syllogisms. Most of the things about which we make decisions, and into which therefore we inquire, present us with alternative possibilities. For it is about our actions that we deliberate and inquire and all our actions have a contingent character; hardly any of them are determined by necessity. (Aristotle, 1954, p. 28)

Probability starts from the premise(s), especially the major premise which is often generally true, but not necessarily or absolutely true, e.g. the Maxim given by Aristotle, "There is no man in all things prosperous" (ibid: 136). The conclusion deduced thereafter, for example, "The king is not in all things prosperous", bears the feature of probability as well, although it is highly acceptable.

We have so far briefly stated the two features of enthymeme: incompleteness and probability. With either of them being met, we can treat the syllogism as a rhetorical one. However, it is not difficult to find that a typical rhetorical syllogism (in contrast to a standard one) needs to satisfy both incompleteness and probability, as illustrated by Yuan \& Jiang (2010) and further evidenced in the following RQ investigation.

\section{Enthymematic Analyses of RQs in Wen Xin Diao Long}

Written by Liu Xie (刘㭷) around 501 AD, The Literary Mind \& the Carving of Dragons is a masterpiece specializing in literary theory and criticism. Liu Xie (about 465-520 AD), a literary theorist and critic in the Northern and Southern Dynasties (420-589), was orphaned in his youth, and never married. From his twenties to thirties, Liu studied Buddhism with Seng You (僧祐) and helped edit sutras at the Dinglin Monastery (定林寺), where Wen Xin Diao Long was completed. The Carving of Dragons comments systematically and extensively previous literary works, analyzing their success and failure; at the same time, the book insightfully addresses many important theoretical issues on literature and rhetoric. Admiration for Liu Xie, throughout the ages, has been incessant, as evidenced lately in Shih (2015, p. 1xi), "He inspires the reader not only by the content of his work, but also by his incomparable style."

The Carving of Dragons consists of fifty essays ${ }^{3}$ which are divided into four parts by modern scholars: "General Principles" (总论), “Stylistic Theories" (文体论), “Writing Theories" (创作论) and "Literary Criticism" (文 学评论). Each essay features a main body and conclusion/“The Tsan” (“赞”), from about 600 to 1000 words. There are three complete English translations of Wen Xin Diao Long: The Literary Mind and the Carving of Dragons (Shih, 1959), The Book of Literary Design (Wong, Lo, \& Lam, 1999), and Dragon-Carving and the Literary Mind (Yang, 2003). We choose the latest revised edition (2015) of Vincent Yu-chung Shih, since it is the first full English version and also the first published translation in the western world. Professor Shih's translation has received high evaluation. Hawkes (1969, p. 331) comments that the language of Shih is more smooth, felicitous and readable. Italian Chinese scientist Lanciotti (1960, pp. 58-59) also highly appreciates this version and believes that its detailed index and accurate annotation are of very practical value to the researchers of Chinese literary theory.

After both autonomous screening in AntConc v3.5.7, and manual verification, ${ }^{4}$ we find 116 rhetorical questions from this work. According to the specific strategies under the principle of purposive sampling in qualitative research, three representative essays are selected from The Literary Mind and the Carving of Dragons: "On Tao, the Source" (Ch. I), "Literary Flaws" (Ch. XLI), and "The Capacity of a Vessel" (Ch. XLIX). After closely examining these articles, we have located all the RQs in them and present their respective number in the following table:

Table 2. The Number of RQs in the Selected Wen Xin Diao Long Essays

\begin{tabular}{lc}
\hline \multicolumn{1}{c}{ Title } & The Number of RQs \\
\hline On Tao, the Source (《原道》) & 4 \\
\hline Literary Flaws (《指瑕》) & 5 \\
\hline The Capacity of a Vessel ( 《程器》) & 8 \\
\hline
\end{tabular}

In the following subsections, we select five typical rhetorical questions (one from "On Tao, the Source", and two from each of the other two essays), with the English translations from Vincent Yu-chung Shih (2015), and their Chinese counterparts from Zhou Zhenfu (2013). Although

3 In Shih's (2015) edition, Carving of Dragons has 49 chapters, which, he deems, are used in the treatment of literature, while the fiftieth chapter (the Preface) states Liu Xie's purpose and reasons for writing this book. According to the division by Liu Xie in the original "Preface" (Ch. L), Zhou (2013) divides Carving of Dragons into 50 chapters, including "General Principles" (总论, Ch. I-V), "Stylistic Theories" (文体论, Ch. VI-XXV), "Writing Theories" (创作论, Ch. XXVI-XLIV) and "Literary Criticism" (文学评论, Ch. XLV-L).

4 Since there is no electronic version of Zhou Zhenfu's edition (2013), we have to screen the RQs in it manually, while other two versions, Wen Xin Diao Long (Wang, 2014) and The Translation and Annotation of Wen Xin Diao Long (Wang \& Zhou, 2016), are used for autonomous screening in AntConc v3.5.7. After that, RQs in all the three versions are verified manually. And of all the 116 RQs, 17 are answered by Liu himself; the other 99 have no answers at all. 
limited in number, the samples to be enthymematically analyzed are representative.

\section{1. "On Tao, the Source"}

"On Tao, the Source", the beginning essay in Carving of Dragons, is generally viewed as the soul of the entire book. It discusses the origin of wen (文), which is similar to literariness/adornment/pattern, depending on the corresponding contexts. Liu Xie deems that wen exists everywhere, not only in human writings, but in natural phenomena as well. First of all, when describing wen in nature, Liu holds that "It is born together with heaven and earth" and everything contains it, including animals and plants. Besides, this kind of feature is just naturally formed, as it belongs to "the pattern of Tao (道)". Of all the four rhetorical questions located in this passage, three are found to have been answered by Liu himself; only the following is left with no answer at all, leaving much for deduction. ${ }^{5}$

(1) Now if things which are devoid of consciousness express themselves so extremely decoratively, can that which is endowed with mind lack a pattern proper to itself?

夫以无识之物, 郁然有彩, 有心之器, 其无文欵?

Fu yi wu shi zhi wu, yu ran you cai, you xin zhi qi, qi wu wen yu?

This rhetorical question appears at the end of the second paragraph. Here, Liu Xie wants to convey that if the unconscious things in nature all have their patterns, such as dragons and phoenixes, tigers and leopards, clouds and plants (described at the beginning of this paragraph), then man should have more reason to exhibit wen, because he alone is "endowed with mind" or "with spirituality" (mentioned in Para. One). This RQ actually is a typical enthymeme, satisfying both traits of probability and incompleteness. The probability seems highly acceptable; ${ }^{6}$ the incompleteness needs to be tackled via syllogism for a further comprehension:

Implied MP: Humans are higher than non-humans.

Expressed mp: Things devoid of consciousness express themselves so extremely decoratively.

Suggested Con: (That which is endowed with mind cannot lack a pattern proper to itself.)

Man endowed with mind should have more reason to exhibit proper wen.

In this rhetorical syllogism, we treat the conclusion (Con) as suggested or indirectly expressed, because we have to transform the RQ into its corresponding statement. And

5 RQ in Western rhetoric often strictly refers to the question unanswered; but its Chinese equivalent can also include the question answered by the author himself. As the texts examined are in Chinese, we prefer to use the broad meaning of RQ, covering both question types; yet, all the analyzed samples are universally acknowledged RQs (with no answers).

6 We will not offer interpretations of probability in the course of the sample analyses, as it is not the focus of this article. But after finishing the analyses, we find that the incompleteness of the enthymematic RQ contributes to the acceptability of the probable assertion.
"That which is endowed with mind" actually refers to man, as Liu Xie in Paragraph One says, "Man, and man alone, forms with these (heaven and earth) the Great Trinity, and he does so because he alone is endowed with spirituality. $\mathrm{He}$ is the refined essence of the five elements -- indeed, the mind of the universe." (Shih, 2015, p. 8) So we offer a similar interpretation which is actually one of Liu's core assertions forcefully raised with the form of RQ. Readers, recognizing the beautiful patterns displayed by animals and plants, cannot fail to understand the author's question in his expected way: Humans have mind and language which give them a more complex way to express themselves -writing -- where proper patterns/wen should thrive. As RQ helps focus on one's topic (Huang 1999), it is easier than its straightforward counterpart to draw the audience's attention, engage them in thinking, and thus enhance the persuasive power. The minor premise (mp) is explicitly expressed in the first half of the sentence. And the major premise (MP) should be the implied assumption: "Humans are higher than non-humans." which, though not without controversy, can be arrived at syllogistically via the working of the RQ.

\section{2. "Literary Flaws"}

“Literary Flaws" is the forty-first essay. “Flaws” (瑕) are spots of jade, metaphorically referring to faults or defects in writing. At the beginning, Liu Xie puts forward the view that articles have great influence, thus authors should be cautious and rigorous. Then he blames two kinds of faults: the faults in writing and those in annotating. When it comes to the former, after reading previous articles carefully, Liu finds that, since earlier times, scholars have always been unable to be perfect in thinking, thus their literary writing is rarely without any flaws. Later, he mainly cites Cao Zhi, son of King Cao Cao and other four previous writers ${ }^{7}$ to illustrate that, in writing, many clumsy expressions (collocations, metaphors or analogies) are difficult to cover up. The following rhetorical question is employed to introduce his criticism of those authors' carelessness in diction:

(2) Because sound does not depend on wings, it is very easy for it to fly; and because feeling does not depend on roots, it is not at all difficult for it to gain a firm footing. Since this applies particularly to literary writing, should one not compose with the utmost caution?

然则声不假翼，其飞甚易；情不待根，其固罒难； 以之垂文, 可不慎竹?

7 Here, Liu Xie cites five renowned writers: Cao Zhi, Zuo Si, Pan Yue, Cui Yuan, and Xiang Xiu. Cui Yuan (崔瑗) was in the Eastern Han Dynasty (25 AD-220 AD); Cao Zhi (曹植) was in the Three Kingdoms Period (220 AD-280 AD); Xiang Xiu (向秀) was between the Wei and Jin Dynasties; Zuo Si (左思) and Pan Yue (潘岳) were in the Western Jin Dynasty (266 AD-316 AD). Liu Xie listed these five figures to illustrate the inappropriateness of their articles: using humble expressions for noble people, using words suitable to the elderly for the younger generation, and using immoderate analogy, etc. 
Ran ze sheng bu jia yi, qi fei shen yi; qing bu dai gen, qi gu fei nan; yi zhi chui wen, ke bu shen yu?

Quintilian (1921, p. 379) points out that one of the functions of rhetorical questions is to express dissatisfaction. Here, Liu Xie, is actually making the prelude of his criticism against the lack of caution in writing and its severe consequence, since sounds and feelings are easily spread and it is literary writing that passes them down. The reasoning process of this view can also be restored by rhetorical syllogism:

Implied MP: Anything that can spread sounds and feelings should be treated with the utmost caution.

Expressed mp: Literary writing can particularly spread sounds and feelings.

Suggested Con: (One should compose with the utmost caution.)

Literary writing should be treated with the utmost caution.

For this RQ, "Since this applies particularly to literary writing, should one not compose with the utmost caution?", we are justified to treat the reason part as minor premise and with the context, interpret it more clearly as "Literary writing can particularly spread sounds and feelings." The question part we then identify as the suggested or indirectly expressed conclusion, has to be transformed from "[S]hould one not compose with the uttermost caution?" to its declarative counterpart "One should compose with the utmost caution." and further to its passive equivalent "Literary writing should be treated with the utmost caution." The conversion process depends upon readers' keen attention and active participation, which definitely highlights and thus strengthens this conclusion -- actually the thesis of the entire essay. With the directly expressed minor premise and the indirectly suggested conclusion, the implied major premise or assumption can be easily deduced as shown in the upper syllogism.

After that, when it comes to the flaws in annotating, Liu Xie cites two predecessors, the first being Xue Zong, a famous official of $\mathrm{Wu}$ State during the Three Kingdoms Period. Xue is relatively close to the time when Zhang Heng composed “Hsi-ching fu" (《西京赋》), ${ }^{8}$ but Xue's annotation for it is with obvious errors. The meaning of words in such a recent prose is misinterpreted when making annotations, let alone that in a classical text which is profound and complicated. Liu Xie uses a rhetorical question to remind people who are committed to literature that they should not take a casual attitude towards the enquiry into classical texts:

(3) $[\mathrm{T}] \mathrm{he}$ art of poetry writing is of rather intimate concern to us, and yet it has been the subject of enormous misconceptions; how is it possible then

8 "Hsi-ching fu" (《西京赋》) was written by Zhang Heng, a writer and scientist in the Eastern Han Dynasty. It describes the prosperity of Chang'an, satirizes the extravagant atmosphere of the society. to eliminate errors when one comes to the enquiry into classical text?

辞赋近事, 而千里致差; 况钻灼经典, 能 不谬 哉?

Ci fu jin shi, er qian li zhi cha; kuang zuan zhuo jing dian, neng bu miu zai?

With this RQ, Liu intends to warn the literati that they should not be remiss while delving into classical texts; otherwise, they would make regrettable flaws. The rhetorical syllogism could be unfolded as follows:

Implied MP: The remote is more prone than the intimate to being the subject of misconceptions.

Expressed mp: The art of intimate poetry writing has been the subject of enormous misconceptions.

Suggested Con: (It is impossible to eliminate errors when coming to the enquiry into classical text.)

Classical text is more prone to being the subject of misconceptions.

From the first half of this RQ, "[T]he art of poetry writing...misconceptions", the expressed minor premise can be located. The second half, the question itself, "how is it possible...classical text?", emphatically suggests its declarative counterpart, the conclusion -- "It is impossible to eliminate errors when one comes to the enquiry into classical text." which is equivalent to "Classical text is more prone to being the subject of misconceptions." The major premise, then, is assumed or implied as the common knowledge: "The remote is more prone than the intimate to being the subject of misconceptions." This RQ actually lays the groundwork for the later assertion that if in time "a writer is able to correct himself according to the proper standard, he will have nothing to be ashamed of in the thousand years that follow." (Shih, 2015, p 289) All the above propositions derived from the RQ, whether expressed, suggested or implied, highlight Liu Xie's central point of being serious and precise in writing.

\section{3. "The Capacity of a Vessel"}

"The Capacity of a Vessel" (Cheng-Qi) is the $49^{\text {th }}$ or the last essay in The Literary Mind and the Carving of Dragons. Cheng (程), means "measure" or "weigh"; and $Q i$ (器), refers to "a talented person". Liu Xie here discusses the moral character, literary talent and working competence of literati. In this article, we locate altogether 8 rhetorical questions, the highest frequency of all pieces, and they are used mainly to emphasize the assertion or thesis: Man of letters should possess moral character, political talent (capacity for practical affairs) as well as literary talent, so that they can become role models for others. At that time, literati were criticized for their ornate language without being down-to-earth, and for their reputation of being "careless in the small matters of their lives" (Shih, 2015, p. 347). Liu believes that those accusations are reasonable, but literati should not be the only object to be found fault with. Compared with the 
writers in low rank, those in high rank and position do more harm and should also be reproved. The same stain has been magnified on literati, but has only been glanced at on the generals and powerful ministers, because they occupy high official positions. Therefore, Liu Xie believes that literati, in addition to literary talent and moral character, should also understand political affairs and develop capacity of dealing with practical matters. In the following rhetorical question, Liu Xie cites Jing Jiang of $\mathrm{Lu},{ }^{9}$ an uneducated woman who knows from her weaving the principles of managing a state, to assert that a man making achievements in literature should have better sense of governing affairs.

(4) Ching-chiang of Lu was just a woman of intelligence, but she had sense enough to infer from her weaving principles applicable to the management of a state. How then can it be explained when a man who has made achievements in literature yet knows nothing about government?

鲁之敬姜, 妇人之聪明耳, 然推其机综, 以方治 国，安有丈夫学文，而不达于政事哉？

Lu zhi Jing Jiang, fu ren zhi cong ming er, ran tui qi ji zong, yi fang zhi guo, an you zhang fu xue wen, er bu da yu zheng shi zai?

This long involved rhetorical question (just one sentence in the original Chinese) can be more plainly understood if interpreted enthymematically as follows:

Implied MP: Educated men should know more about state management than uneducated women.

Expressed mp: Jing Jiang, a woman of weaving intelligence, knows state management.

Suggested Con: (It cannot be explained when a man who has made achievements in literature yet knows nothing about government.)

A man achieving in literature should know more about state management.

Actually, this sample starts with an expressed minor premise concerning the intelligent weaving woman, Jing Jiang; and ends with the question itself suggesting the conclusion, a core claim that a man of letters should make better sense of governing affairs. The implied major premise can be readily deduced via the principle of syllogism and we think it is wisely omitted by Liu Xie, not only to achieve conciseness but also to avoid being blamed for his prejudice against women. And as in the previous case, the suggested conclusion is again highlighted or strengthened in the process of readers' transforming the rhetorical question "How then can it be explained when a man who has made achievements in literature yet knows nothing about government?" to its equivalent statement: "It cannot be explained when...", and still further to the expected assertion: "A man achieving in literature should know more about government/state management." Actually, this is what Liu Xie intends to stress out in the

9 Jing Jiang (敬姜) was mother of Wen Bo (文伯) who was the prime minister of State Lu (1043 BC-249 BC). entire passage. To him, men of letters should have adequate knowledge of governmental affairs, exhibit the talent of administering the state, and thus contribute to peace and stability of the country.

Is it enough for a man to "know about government"? Absolutely not. On this basis, Liu puts forward at the end the main idea of the full essay:

(5) The Tsan:

Observe the writers of the past:

Some have achieved perfection in both literary quality and moral virtue!

The fame of some of them rings out in Ch'u in the South, ${ }^{10}$

And the literary excellence of others shakes Liang in the North. ${ }^{11}$

If a writer has no capacity for practical affairs then, despite his laborious carving,

What good will his excellence be to people?

Literature should not only be an ornament for its creator,

But should serve also to glorify the state.

赞曰:

瞻彼前修, 有懿文德。声昭楚南, 采动梁北。

雕而不器, 贞幹谁则? 岂无华身, 亦有光国?

Zan yue:

Zhan bi qian xiu, you yi wen de. Sheng zhao chu nan, cai dong liang bei.

Diao er bu qi, zhen gan shui ze? Qi wu hua shen, yi you guang guo?

Of the two rhetorical questions, we prefer to choose the first one for the enthymematic analysis, together with the previous contextual sentences:

Suggested MP: (A writer with laborious carving but no practical capacity will not be role model to people.)

A/Any writer with both literary and practical capacities will be role model to people.

Expressed mp: Some have achieved perfection in both literary quality and moral virtue/practical capacity.

Implied Con: They are role models to people.

The RQ, "If a writer has no capacity for practical affairs then, despite his laborious carving, what good will his excellence be to people?", actually suggests a declarative sentence as shown in the brackets above, which can be converted to the major premise, "Any writer with both literary and practical capacities will be role model to people." As the conversion has to be achieved by readers themselves, this key proposition (Liu now presents as assumption) gains extra attention and salience. The minor premise, "Some have achieved perfection in both literary quality and moral virtue/practical capacity." is directly

10 Referring to $\mathrm{Qu}$ Yuan (屈原, $339 \mathrm{BC}-278 \mathrm{BC}$, a poet and statesman in the Warring States Time), and Jia Yi (贾谊, 200 BC-168 BC, a statesman and litterateur in the Western Han Dynasty).

11 Referring to Zou Yang (邹阳, 206 BC-129 BC, a litterateur in the Western Han Dynasty), and Mei Sheng (枚乘, ?-140 BC, a writer of sentimental or descriptive composition in the Western Han Dynasty). 
expressed in the first sentence and illustrated by the second one. According to the syllogistic pattern, the conclusion can be deduced as "They (Qu Yuan, Jia Yi, etc.) are role models to people."

In this paragraph, $\mathrm{Qu}$ Yuan and Jia $\mathrm{Yi}$ are taken as examples to illustrate that literati with both literary talent and virtue will be widely known and respected; the example of Zou Yang and Mei Cheng elucidates that people with outstanding literary and political talents will receive plenty of recognition. Therefore, they are all role models for future generations and the most ideal images of literati in Liu Xie's mind. Here, Liu points out that the ideal writer should be brilliant in literature, noble in moral character and distinguished in practical ability. Only in this way can he become a model for later generations, and remain famous in history like Qu Yuan, Jia Yi and other eminent literati. Of all the three propositions in the syllogism, it is not difficult to judge that the major premise, emphatically suggested by the RQ, should be the soul of not only the summary but the entire essay as well.

\section{Conclusions}

Equipped with Aristotle's theory of enthymeme or rhetorical syllogism, we have analyzed, among many others, five typical rhetorical questions in Liu Xie's representative essays of The Literary Mind and the Carving of Dragons, and made two major discoveries. With regard to the form/type, we find that all the selected RQs just have one explicitly expressed proposition, the minor premise, with the other propositions either implied (mostly major premise) or suggested (indirectly expressed). Similar to Aristotle's example of Dorieus, this form can be treated as Type 4 in the table of "Six Incomplete Types of Enthymeme"; but with RQ, we need to interpret the two propositions "omitted" -- as one "implied" and the other "suggested" (more than implied but less than expressed), which is a refinement of the previous researches on the truncation of enthymeme. In terms of the function, actually related to the form, we discover that, besides euphemism (as shown in Ex. 4), all the analyzed RQs achieve a strong logical function via implying or suggesting assumption (as the major premise), providing the solid argument (as minor premise) and suggesting or implying the claim (as conclusion). In the studies of Slot (1993) and Ilie (1994), RQs are discovered to have two specific functions: proposing a common starting point and putting forward arguments (as cited in Henkemans, 2009, p. 15), which not only confirms our first two discoveries, but justifies as well our new finding of "suggesting or implying the claim". Also, our enthymematic analyses have proved that RQ's logical function is meanwhile accompanied by salience or emphasis of the suggested claim or assumption transformed from the question itself, another advance as we have not seen, in the previous scholarship, the clear blending of RQ's emphatic and logical functions. Although we have made these encouraging discoveries, the RQs analyzed via rhetorical syllogism are limited and confined to "On Tao, the Source", "Literary Flaws", and "The Capacity of a Vessel", only three essays of Liu Xie's 50 -piece work. Further exploration, therefore, is expected to be conducted on whether enthymeme is applicable to explaining the rest of his RQs and whether our findings are universal to the rhetorical questions in other classics as well.

\section{Acknowledgements}

We would like to thank very gratefully Prof. Heping Zhao, Mr. Ming'an Luo, and two meticulous peer reviewers, for their appreciative recognition and constructive suggestions. Further, this research project (SJKY19_2247) has been generously supported by the Research Innovation Plan for Postgraduates in Jiangsu Province in 2019, and it is also a sub-project of Ying Yuan's Chinese National Social Science Fund Project: “On Argumentative Textual Functions of Major Tropes and Schemes" (15BYY178).

\section{REFERENCES}

[1] Aristotle. 1954. Rhetoric (W. Roberts, Trans.). New York: Random House.

[2] Cicero. 1954. Rhetorica ad Herennium (H. Caplan, Trans.). London: William Heinemann.

[3] Crowley, S., \& Hawhee, D. 2012. Ancient rhetorics for contemporary students. New York: Pearson Longman.

[4] Frank, J. 1990. You call that a rhetorical question? Journal of Pragmatics, 14 (5), 723-738.

[5] Hawkes, D. 1969. The Literary Mind and the Carving of Dragons (book review). The Journal of Asian Studies, 19 (3): 331-332.

[6] Henkemans, A. F. S. 2009. Manoeuvring strategically with rhetorical questions. In F. H. van Eemeren, \& B. Garssen (Eds.), Pondering on problems of argumentation: Twenty essays on theoretical issues (pp. 15-23). The Netherlands: Springer.

[7] Huang, R. 1999. English rhetoric: An introduction. Shanghai: Shanghai Foreign Language Education Press.

[8] Ilie, C. 1994. What Else Can I Tell You? A Pragmatic Study of English Rhetorical Questions as Discursive and Argumentative Acts. Stockholm: Almqvist \& Wiksell International.

[9] Kraus, M. 2007. From figure to argument: contrarium in roman rhetoric. Argumentation, 21 (1), 3-19.

[10] Lanciotti, L. 1960. The Literary Mind and the Carving of 
Dragons: A Study of Thought and Pattern in Chinese Literature by Liu Hsieh, Vincent Yuchung Shih (book review). East and West, 11 (1): 58-59.

[11] Lanham, R. A. 1991. A handlist of rhetorical terms. London: University of California Press.

[12] Quintilian. 1921. The institutio oratoria. (H. E. Butler, Trans.). Cambridge: Harvard University Press.

[13] Shih, V. Y. C. 2015. The literary mind and the carving of dragons. Hong Kong: The Chinese University Press.

[14] Slot, P. 1993. How can you say that? Rhetorical questions in argumentative texts. Amsterdam: Ifott.

[15] Wang, Y. X., \& Zhou, F. 2016. The translation and annotation of Wen Xin Diao Long. Shanghai: Shanghai Classics Publishing House.

[16] Wang, Z. B. 2014. Wen Xin Diao Long. Beijing: Zhonghua Book Company.

[17] Yuan, Y. 2006. Anatomy of "enthymeme": A key concept in Aristotle's Rhetoric. Rhetoric Study, (5), 23-26+30.

[18] Yuan, Y., \& Jiang, Y. 2010. Rhetorical syllogism and implicature-drawing in pragmatic inference. Foreign Language Teaching and Research, 42 (2), 97-103+160.

[19] Zhao, H. (1994). Rhetorical Invention in "Wen Xin Diao Long”. Rhetoric Society Quarterly, 24 (3/4), 1-15.

[20] Zhou, Z. F. 2013. Modern translation of Wen Xin Diao Long. Beijing: Zhonghua Book Company. 